\title{
Angiographic and Clinical Significance of 'Transient' ST-Segment Depression in the Lateral Chest Leads in Anterior Wall Acute Myocardial Infarction
}

\author{
Akira Tamura, MD; Toru Watanabe, MD; Kimiaki Nagase, MD; \\ Yoshiaki Mikuriya, MD; Masaru Nasu, MD
}

\begin{abstract}
This study aimed to clarify the significance of ST-segment depression in the lateral chest leads in anterior wall acute myocardial infarction (AMI) with ST-segment elevation. A total of 196 patients with their first anterior wall AMI ( $\leq 6 \mathrm{~h}$ ) were divided into 2 groups according to the presence (group A, n=39) or absence (group B, $\mathrm{n}=157$ ) of ST-segment depression $\geq 0.1 \mathrm{mV}$ in $\mathrm{V}_{5}$ and/or $\mathrm{V}_{6}$ on the admission electrocardiogram. Patients with electrocardiographic confounding factors were excluded. No patients had persistent ST-segment depression in the lateral chest leads. Emergency coronary angiography revealed that group A had higher incidences of occlusion of the left anterior descending coronary artery (LAD) proximal to its first septal branch (77\% vs 51\%, $\mathrm{p}<0.01)$ and good collateral circulation than group B $(46 \%$ vs $25 \%, \mathrm{p}<0.05)$. Peak creatine kinase levels were significantly lower in group A than in group B $(2060 \pm 1099$ vs $2873 \pm 2077$ IU/L, p $<0.01)$. Left ventricular ejection fraction in the chronic phase was significantly greater in group A than in group B. Regional wall motion in the infarct region in the chronic phase was better in group A than in group B. These results indicate that patients with 'transient' ST-segment depression in the lateral chest leads in anterior wall AMI had a relatively smaller infarct size, despite their higher incidence of occlusion of the LAD proximal to its first septal branch, because of their higher incidence of good collateral circulation. (Jpn Circ J 1999; 63: 873-876)
\end{abstract}

Key Words: Acute myocardial infarction; Electrocardiography; ST-segment depression

$\mathbf{S}$ T-segment depression in any lead is frequently observed in anterior wall acute myocardial infarction (AMI) and previous reports have shown that patients with this sign have a poor prognosis ${ }^{1-3}$ However, those studies did not differentiate patients with ST-segment depression in the inferior leads from those with STsegment in the lateral chest leads. There may be differences in the significance between the 2 types of ST-segment depression and although there have been many reports with regard to ST-segment depression in the inferior leads in anterior wall AMI,-21 the angiographic and clinical significance of ST-segment depression in the lateral chest leads in anterior wall AMI has not yet been fully investigated, especially in the case of AMI accompanied by ST-segment elevation in the precordial leads. Accordingly, the present study aimed to clarify the angiographic and clinical features of patients with ST-segment depression in the lateral chest leads on the admission electrocardiogram (ECG) in anterior wall AMI with ST-segment elevation.

\section{Methods}

\section{Patients}

Between January 1989 and December 1997, 252 patients with anterior wall AMI were admitted within $6 \mathrm{~h}$ of the onset of chest pain. The data regarding these patients was prospectively entered into a computer database. Patients

(Received January 11, 1999; revised manuscript received July 12, 1999; accepted August 3, 1999)

Second Department of Internal Medicine, Oita Medical University, Oita, Japan

Mailing address: Akira Tamura, MD, Second Department of Internal Medicine, Oita Medical University, Hasama, Oita 879-5593, Japan meeting the following criteria were selected for this study: (1) typical chest pain lasting $\geq 30 \mathrm{~min}$; (2) ST-segment elevation $\geq 0.2 \mathrm{mV}$ in $\geq 2$ contiguous precordial leads on the admission ECG; (3) increase in serum creatine kinase (CK) level more than twice the normal value; (4) no previous myocardial infarction (MI); (5) no confounding ECG findings, such as left ventricular (LV) hypertrophy (confirmed by echocardiography), left or right bundle branch block, intraventricular conduction disturbance, ventricular rhythm and Wolf-Parkinson-White syndrome, or poor-quality ECG recordings; (6) no other heart or lung disease; and (7) identification of the infarct-related lesion by emergency coronary arteriography. In total, 196 patients (141 men and 55 women, mean age $63 \pm 10$ years) met these criteria. The patients were classified into 2 groups according to the presence (group A, $n=39$ ) or absence (group B, n=157) of STsegment depression $\geq 0.1 \mathrm{mV}$ in $\mathrm{V} 5$ and/or $\mathrm{V}_{6}$ on the admission ECG. Of 37 group A patients still living, none had persistent ST-segment depression in the lateral chest leads during the in-hospital period.

Standard 12-Lead ECG

Standard 12-lead ECGs were recorded at a paper speed of $25 \mathrm{~mm} / \mathrm{s}$ and a standardization of $10 \mathrm{~mm}=1 \mathrm{mV}$. The magnitude of ST-segment elevation or depression relative to the TP-segment was measured to the nearest $0.5 \mathrm{~mm}$ at $80 \mathrm{~ms}$ after the $\mathrm{J}$ point. All ECGs were analyzed by the consensus of 2 observers who were blinded to all clinical and angiographic data.

\section{Emergency Coronary Arteriograms}

Emergency coronary arteriography was performed using either the Judkins or Amplatz techniques. Multiple projec- 
Table 1 Clinical Characteristics

\begin{tabular}{lccc}
\hline \hline & $\begin{array}{c}\text { Group A } \\
(n=39)\end{array}$ & $\begin{array}{c}\text { Group B } \\
(n=157)\end{array}$ & p value \\
\hline Age (years) & $62 \pm 9$ & $63 \pm 11$ & $N S$ \\
Male & $26(67 \%)$ & $115(73 \%)$ & $N S$ \\
Time to admission (min) & $142 \pm 72$ & $154 \pm 82$ & $N S$ \\
Peak CK (IU/L) & $2060 \pm 1099$ & $2873 \pm 2077$ & $<0.01$ \\
Postinfarction angina & $2(5 \%)$ & $2(1 \%)$ & $N S$ \\
Re-infarction & $1(3 \%)$ & $4(3 \%)$ & $N S$ \\
In-hospital death & $2(5 \%)$ & $10(6 \%)$ & $N S$ \\
\hline
\end{tabular}

Data presented are means \pm SD or number (\%).

$C K$, creatine kinase; NS, not significant.

Table 2 Emergency Coronary Angiographic Findings

\begin{tabular}{lccc}
\hline \hline & $\begin{array}{c}\text { Group A } \\
(n=39)\end{array}$ & $\begin{array}{c}\text { Group B } \\
(n=157)\end{array}$ & p value \\
\hline TIMI 3 & $4(10 \%)$ & $11(7 \%)$ & $N S$ \\
Good collaterals & $18(46 \%)$ & $40(25 \%)$ & $<0.05$ \\
Multivessel disease & $15(38 \%)$ & $45(29 \%)$ & $N S$ \\
LAD occlusion proximal to its first SB & $30(77 \%)$ & $80(51 \%)$ & $<0.01$ \\
LAD occlusion proximal to its first DB & $21(54 \%)$ & $71(45 \%)$ & $N S$ \\
Reperfusion therapy & & & \\
PTCR & $31(79 \%)$ & $107(68 \%)$ & $N S$ \\
PTCA & $15(38 \%)$ & $82(52 \%)$ & $N S$ \\
TIMI 3 after reperfusion therapy & $27(69 \%)$ & $113(72 \%)$ & $N S$ \\
\hline
\end{tabular}

$L A D$, left anterior descending coronary artery; $S B$, septal branch; $D B, d i$ agonal branch; PTCR, percutaneous transluminal coronary recanalization; PTCA, percutaneous transluminal coronary angioplasty.

tions were recorded to ensure optimal visualization of the coronary vessels. The coronary flow in the infarct-related artery was graded according to the classification used in the Thrombolysis In Myocardial Infarction (TIMI) trial22 The grade of collateral filling in the left anterior descending coronary artery (LAD) was determined according to the criteria of Rentrop et $\mathrm{al}^{23}$; collateral circulation of grade of 2 or 3 was defined as 'good'. After angiographic confirmation of total or subtotal occlusion of the LAD, intracoronary isosorbide dinitrate was administered, followed by intracoronary urokinase or tissue plasminogen activator. If reperfusion was not successful, coronary angioplasty was performed. Forty-two patients underwent direct angioplasty. Successful reperfusion was defined as the establishment of TIMI grade 3 flow in the infarct-related artery.

\section{Cardiac Catheterization in the Chronic Phase}

Of 196 patients studied, 173 (88\%) underwent coronary arteriography and left ventriculography about 1 month after AMI. Left ventriculograms performed in the $30^{\circ}$ right anterior oblique projection were analyzed for the LV ejection fraction (LVEF) and regional wall motion by an experienced cardiologist who was unaware of the patient's data. The LVEF was calculated by the area-length method? 4 Regional wall motion of the LV was calculated by the centerline method 25 ; that is, it was measured at 100 equidistant chords perpendicular to a center line drawn midway between the end-diastolic and end-systolic LV silhouettes and numbered clockwise from the anterior aortic valve. To normalize for heart size, the motion at each chord was divided by the length of the end-diastolic perimeter to yield a dimensionless shortening fraction. Because comparison of different regions requires that motion values be comparable, the normalized or shortening fraction of each chord was converted into units of standard

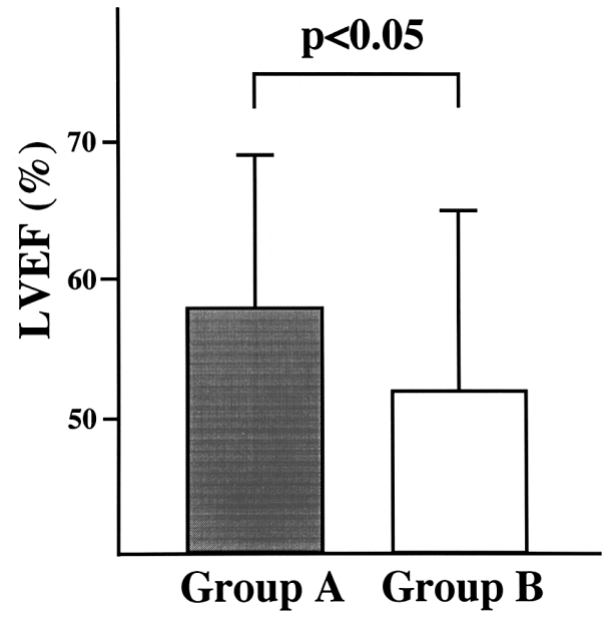

Fig 1. Comparison of left ventricular ejection fraction (LVEF) in the chronic phase.

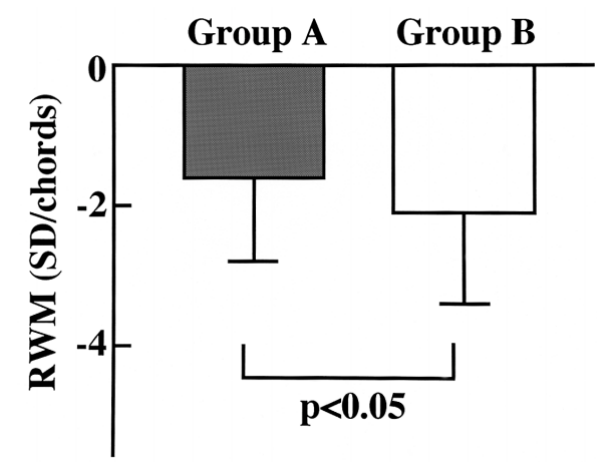

Fig 2. Comparison of regional wall motion (RWM) in the anterolateral and apical region in the chronic phase.

deviation (SD) from the normal group mean. Regional wall motion was expressed as the mean values of SD/chords in the anterolateral and apical region (chords 21-60).

\section{Cardiac Enzyme Measurement}

Blood samples were obtained every $3 \mathrm{~h}$ during the first $24 \mathrm{~h}$ and once daily from the second day until a normal value was obtained for determination of the peak serum $\mathrm{CK}$ activity.

\section{Statistical Analysis}

Continuous variables are expressed as mean values \pm SD. Categorical data were analyzed by the Fisher's exact test or chi-square test. Continuous variables were analyzed by the unpaired t test. A p value $<0.05$ was considered statistically significant.

\section{Results}

Clinical characteristics are shown in Table 1. There were no differences between the 2 groups in age, gender, and the time elapsed from the onset of chest pain to admission. Peak CK levels were significantly lower in group A than in group B $(2060 \pm 1099$ vs $2873 \pm 2077$ IU/L, p<0.01). The incidences of postinfarction angina and re-MI during the in-hospital period were similar between the 2 groups (5\% vs $1 \%$ and $3 \%$ vs $3 \%$, respectively). In-hospital mortality was similar in the 2 groups (5\% vs $6 \%$ ). The causes of 
death in group A were ventricular fibrillation $(n=1)$ and congestive heart failure $(\mathrm{n}=1)$, whereas in group $\mathrm{B}$ they were congestive heart failure $(n=5)$, cardiac rupture $(n=4)$, and cerebrovascular disorder $(\mathrm{n}=1)$.

Emergency coronary angiography (Table 2) revealed that group A had a higher incidence of occlusion of the LAD proximal to its first septal branch $(77 \%$ vs $51 \%$, $\mathrm{p}<0.01)$ and better collateral circulation than group B $(46 \%$ vs $25 \%, \mathrm{p}<0.05)$. There were no differences in the incidences of multivessel disease and occlusion of the LAD proximal to its first diagonal branch between the 2 groups (38\% vs $29 \%$ and $54 \%$ vs $45 \%$, respectively). The rate of establishment of TIMI grade 3 flow after reperfusion therapy was similar in the 2 groups (69\% vs $72 \%$ ).

There were no differences in age, gender, time elapsed from the onset of chest pain to admission, and the rate of unsuccessful reperfusion therapy between the 2 groups undergoing coronary arteriography and left ventriculography about 1 month after AMI. The incidence of TIMI grade 3 flow on coronary arteriography in the chronic phase was similar between the 2 groups ( $84 \%$ vs $85 \%$ ). The LVEF in the chronic phase was significantly greater in group A than in group B (58 $\pm 11 \%$ vs $52 \pm 13 \%$, p $<0.05)$ (Fig 1). Regional wall motion in the anterolateral and apical region was significantly less reduced in group A than in group B $(-1.6 \pm 1.2$ vs $-2.1 \pm 1.3, \mathrm{p}<0.05)$ (Fig 2$)$.

\section{Discussion}

In the present study, patients with ST-segment depression in the lateral chest leads on the admission ECG had a higher incidence of occlusion of the LAD proximal to its first septal branch than those without it. However, despite this angiographic feature, patients with this type of STsegment depression had a smaller infarct size and less regional wall motion abnormality in the chronic phase than those without it. This is thought to be partly because $56 \%$ of the former had TIMI grade 3 or good collateral circulation on the initial coronary arteriogram. As the present study did not include patients with persistent ST-segment depression in the lateral chest leads, our results represent the angiographic and clinical features of patients with anterior wall AMI showing 'transient' ST-segment depression in the lateral chest leads. The lack of patients with 'persistent' ST-segment depression in the lateral chest leads is probably because we excluded patients with LV hypertrophy or previous MI. The previous damage to the myocardium caused by ischemia or hypertension could be a major cause of 'persistent' ST-segment depression in the lateral chest leads after AMI. The effect of myocardial salvage by successful revascularization could be an alternative important cause of the lack of 'persistent' ST-segment depression in the lateral chest leads in the present study.

\section{Mechanisms of ST-Segment Depression in the Lateral Chest Leads in Anterior Wall AMI With ST-Segment Elevation}

Several factors could contribute to ST-segment depression in the lateral chest leads in anterior wall AMI with STsegment elevation. First, as the lateral chest leads face the lower anterolateral and apical region, transmural ischemia in this region is expected to cause ST-segment elevation in the lateral chest leads. On the other hand, non-transmural ischemia in this region is expected to cause ST-segment depression in the lateral chest leads. Therefore, it is reason- able that patients with ST-segment depression in the lateral chest leads have less regional wall motion abnormality in the anterolateral and apical region. Second, additional remote ischemia caused by multivessel disease may produce ST-segment depression in the lateral chest leads. However, as the incidence of multivessel disease was similar between patients with and without this type of STsegment depression, this phenomenon is unlikely to strongly influence ST-segment deviation in the lateral chest leads. Third, ST-segment elevation in the right chest leads produced by transmural ischemia in the anterior septum perfused by septal branches can produce reciprocal STsegment depression in the lateral chest leads ${ }^{26}$ Indeed, in the present study, the majority of patients with ST-segment depression in the lateral chest leads had an occlusion of the LAD proximal to its first septal branch. In group B patients with an occlusion of the LAD proximal to its first septal branch, the force of the current of injury produced by transmural ischemia in the lower anterolateral and apical region, which would produce ST-segment elevation in the lateral chest leads, might have exceeded the force of the current of injury produced by transmural ischemia in the anterior septum, resulting in absence of ST-segment depression in the lateral chest leads.

\section{In-Hospital Prognosis}

Despite their higher incidence of proximal LAD occlusion, patients with 'transient' ST-segment depression in the lateral chest leads had a relatively smaller infarct size because of their higher incidence of good collateral circulation, and are expected to be at increased risk of postinfarction angina and re-MI if a high-grade residual stenosis persists in the infarct-related vessel after the acute phase. Furthermore, because the majority of these patients appear to have an occlusion of the LAD proximal to its first septal branch, their prognosis is expected to be poor. However, contrary to our expectations, in the present study the inhospital mortality and the incidences of postinfarction angina and re-MI during the in-hospital period did not differ significantly between patients with and without STsegment depression in the lateral chest leads on the admission ECG, which might be because about $50 \%$ of the patients underwent emergency coronary angioplasty. Successful emergency coronary angioplasty might have decreased the incidence of postinfarction angina and re-MI, resulting in improvement in the prognosis of those patients.

\section{$S T$-Segment Depression in the Inferior}

Leads Versus in the Lateral Leads

Patients with ST-segment depression in the inferior leads in anterior wall AMI have been shown to have a higher incidence of proximal LAD occlusion, 15,18,20,21 a larger infarct size, $, 8,12,13,19$ and a poorer prognosis. $6,8,12,19$ Therefore, the frequency of patients with ST-segment depression in the inferior leads could affect our results. However, in the present study, there was no difference in the frequency of patients with ST-segment depression in the inferior leads between patients with and without ST-segment depression in the lateral chest leads. Considering the results of the present study and previous studies with regard to STsegment depression in the inferior leads in anterior wall $\mathrm{AMI}, 4,6,12,13,19$ there may be some differences in infarct size and prognosis between patients with ST-segment depression in the inferior leads and those with ST-segment depression in the lateral chest leads. Further investigation is 
needed to precisely clarify any differences in clinical features according to the site of ST-segment depression in anterior wall AMI.

\section{Study Limitations}

First, group B included both patients without STsegment deviation in the lateral chest leads and those with ST-segment elevation in these leads. Therefore, further studies are needed to clarify whether there is any angiographic and clinical difference according to the type of STsegment deviation in the lateral chest leads (ie, ST-segment elevation, no ST-segment deviation, and ST-segment depression). Second, this study included only patients with anterior wall AMI showing ST-segment elevation on the admission ECG. Therefore, our results cannot be applied to anterior wall AMI patients without ST-segment elevation on the admission ECG.

\section{Conclusions}

The present study clarified the angiographic and clinical features of patients with 'transient' ST-segment depression in the lateral chest leads in anterior wall AMI with STsegment elevation; that is, they had a relatively smaller infarct size, despite their higher incidence of occlusion of the LAD proximal to its first septal branch, because of their higher incidence of good collateral circulation.

\section{References}

1. Willich SN, Stone PH, Muller J, Tofler GH, Crowder J, Parker C, et al: High-risk subgroups of patients with non-Q wave myocardial infarction based on direction and severity of ST segment deviation. Am Heart J 1987; 114: 1110-1119

2. Gheorghiade M, Shivkumar K, Schultz L, Jafri S, Tilley B, Goldstein S: Prognostic significance of electrocardiographic persistent ST depression in patients with their first myocardial infarction in the placebo arm of the Beta-Blocker Heart Attack trial. Am Heart $J$ 1993; 126: $271-278$

3. Krone RJ, Greenberg H, Dwyer EM, Kleiger RE, Boden WE, and the Multicenter Diltiazem Postinfarction Trial Research Group: Longterm prognostic significance of ST segment depression during acute myocardial infarction. J Am Coll Cardiol 1993; 22: 361 - 367

4. Pichler M, Shah PK, Peter T, Singh B, Berman D, Shellock F, et al: Wall motion abnormalities and electrocardiographic changes in acute transmural myocardial infarction: implications of reciprocal ST segment depression. Am Heart J 1983; 106: 1003-1009

5. Billadello JJ, Smith JL, Ludbrook PA, Tiefenbrunn AJ, Jaffe AS, Sobel BE, et al: Implications of 'reciprocal' ST-segment depression associated with acute myocardial infarction identified by positron tomography. J Am Coll Cardiol 1983; 2: 616-624

6. Jennings K, Reid DS, Julian DG: 'Reciprocal' depression of the ST segment in acute myocardial infarction. BMJ 1983; 287: 634-637

7. Camara EJN, Chandra N, Ouyang P, Gottlieb SH, Shapiro EP: Reciprocal ST change in acute myocardial infarction: assessment by electrocardiography and echocardiography. J Am Coll Cardiol 1983; 2: $251-257$

8. Haraphongse M, Tanomsup S, Jugdutt BI: Inferior ST segment depression during acute anterior myocardial infarction: clinical and angiographic correlations. J Am Coll Cardiol 1984; 4: 467-476

9. Furguson DW, Pandian N, Kioschos JM, Marcus ML, White CW: Angiographic evidence that reciprocal ST-segment depression during acute myocardial infarction does not indicate remote ischemia: analysis of 23 patients. Am J Cardiol 1984; 53: 55-62

10. Crawford $\mathrm{MH}$, O'Rourke RA, Grover FL: Mechanism of inferior electrocardiographic ST-segment depression during acute anterior myocardial infarction in a baboon model. Am J Cardiol 1984; 54: $1114-1117$

11. Brymer JF, Khaja F, Marzilli M, Goldstein S, Alban J: 'Ischemia at a distance' during intermittent coronary artery occlusion: a coronary anatomic explanation. J Am Coll Cardiol 1985; 6: 41-45

12. Dewhurst NG, Muir AL: Clinical significance of 'reciprocal' S-T segment depression in acute myocardial infarction: Relative contributions of infarct size and ischemia at a distance. Am J Med 1985; 78: $765-770$

13. Katz R, Conroy RM, Robinson K, Mulcahy R: The aetiology and prognosis implications of reciprocal electrocardiographic changes in acute myocardial infarction. Br Heart J 1986; 55: 423-427

14. Quyyumi AA, Crake T, Rubens MB, Levy RD, Rickards AF, Fox $\mathrm{KM}$ : Importance of 'reciprocal' electrocardiographic changes during occlusion of left anterior descending coronary artery: Studies during percutaneous transluminal coronary angioplasty. Lancet 1986; 1: 347-350

15. Lew AS, Hod H, Cercek B, Shah PK, Ganz W: Inferior ST-segment changes during acute anterior myocardial infarction: a marker of the presence or absence of concomitant inferior wall ischemia. $\mathrm{J} \mathrm{Am} \mathrm{Coll}$ Cardiol 1987; 10: 519-526

16. Hiasa Y, Wada T, Hamai K, Nakaya Y, Mori H: ST-segment depression in inferior ECG leads during percutaneous transluminal coronary angioplasty for left anterior descending artery. Clin Cardiol 1988; 11: 614-618

17. Norell MS, Lyons JP, Gardener JE, Layton CA, Balcon R: Significance of 'reciprocal' ST segment depression: left ventriculographic observations during left anterior descending coronary angioplasty. J Am Coll Cardiol 1989; 13: 1270-1274

18. Birnbaum Y, Solodky A, Herz I, Kusniec J, Rechavia E, Sulkes J, et al: Implications of inferior ST-segment depression in anterior acute myocardial infarction: electrocardiographic and angiographic correlation. Am Heart J 1994; 127: 1467-1473

19. Willems JL, Willems RJ, Willems GM, Arnold AER, de Werf FV, Verstraete M, for the European Cooperative Study Group for Recombinant Tissue-type Plasminogen Activator: Significance of initial ST segment elevation and depression for the management of thrombolytic therapy in acute myocardial infarction. Circulation 1990; 82: $1147-1158$

20. Tamura A, Kataoka H, Mikuriya Y, Nasu M: Inferior ST segment depression as a useful marker for identifying proximal left anterior descending artery occlusion during acute anterior myocardial infarction. Eur Heart J 1995; 16: 1795-1799

21. Tamura A, Mikuriya Y, Kataoka H, Nagase K, Nasu M: Emergen coronary angiographic findings of patients with ST depression in the inferior or lateral leads, or both, during anterior wall acute myocardial infarction. Am J Cardiol 1995; 76: 516-517

22. The TIMI Study Group: The Thrombolysis in Myocardial Infarction (TIMI) trial: phase I finding. N Engl J Med 1985; 312: 932-936

23. Rentrop KP, Cohen M, Blanke H, Phillips RA: Changes in collateral channel filling immediately after controlled coronary artery occlusion by an angioplasty balloon in human subjects. J Am Coll Cardiol $1985 ; 5: 587-592$

24. Kennedy JW, Trenholme SE, Kasser IS: Left ventricular volume and mass from single-plane cineangiocardiograms: a comparison of antero-posterior and right anterior oblique methods. Am Heart $J$ 1970; 80: $343-352$

25. Sheehan FH, Bolson EL, Dodge HT, Mathey DG, Schofer J, Woo HW: Advantages and applications of the centerline method for characterizing regional ventricular function. Circulation 1986; 74: 293 305

26. Tamura A, Kataoka H, Mikuriya Y, Nasu M: Electrocardiographic findings in a patient with pure septal infarction. Br Heart J 1991; 65: $166-167$ 